\title{
Era uma vez... contos de fadas e psicodrama auxiliando alunos na conclusão do curso médico
}

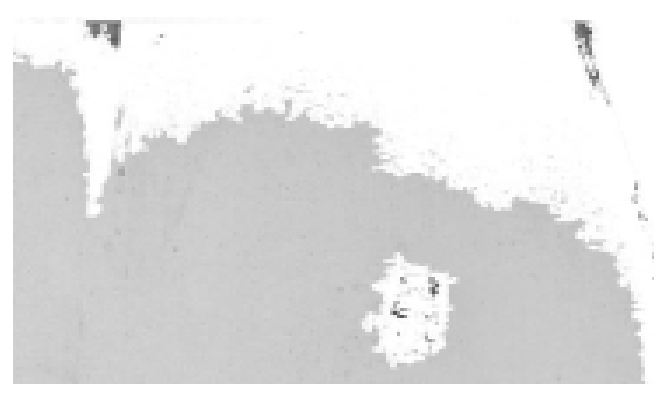

\author{
Ana Teresa de Abreu Ramos-Cerqueira ${ }^{1}$ \\ Maria Cristina Pereira Lima ${ }^{2}$ \\ Albina Rodrigues Torres ${ }^{3}$ \\ José Roberto Tozoni Reis ${ }^{4}$ \\ Neusa Maria Vilela Fonseca
}

RAMOS-CERQUEIRA, A. T. A. et al. Once upon a time... fairy tales and psychodrama to help students at the end of the medical course, Interface - Comunic., Saúde, Educ., v.9, n.16, p.81-9, set.2004/fev.2005.

The final segment of the course is an especially stressful period for medical students, as it places them vis à vis a range of anguishing situations: the end of their days as students, the acquisition of new responsibilities and residency exams. So as to help them through this stage, the Botucatu Medical School (FMB - Faculdade de Medicina de Botucatu) has developed a number of sheltering strategies for its students. This paper describes one activity in which psychodrama was used to facilitate the expression of the feelings and emotions experienced by students at the end of their course. For two years running, sociodrama sessions were held with all the students in the sixth (i.e., last) year of the Botucatu Medical School course. Fairy tales were used as a tool for students to identify their evolution at the institution and the moment they were experiencing. Dramatization of the fairy tales enabled students to share their experiences and worries, many of which where common to several of them and typical of their context. The analysis of the fairy tales focused mainly on projective aspects of the groups; the conclusions pointed to the need for a larger number of arenas for meetings and interchange between students and teachers.

KEY-WORDS: Medical education; mental health; psychodrama; sociodrama; internship and residence.

O término do curso representa um período especialmente estressante para estudantes de Medicina, colocando-os perante diversas angústias: deixar de ser aluno, ter novas responsabilidades e enfrentar o exame de residência. Com o intuito de auxiliá-los nesta fase, foi desenvolvida na Faculdade de Medicina de Botucatu (FMB) uma série de estratégias de acolhimento para os estudantes. Este trabalho descreve uma atividade na qual se utilizou o Psicodrama como facilitador da expressão dos sentimentos e emoções experimentadas ao final do curso. Por dois anos consecutivos foram realizadas sessões de Sociodrama com o conjunto dos alunos do $6^{\circ}$ ano do curso médico da FMB. Utilizaram-se Contos de Fadas como recurso para que os estudantes identificassem sua trajetória na instituição e o momento que estavam vivendo. A dramatização dos contos possibilitou a troca de experiências entre os alunos e o acolhimento de suas angústias, muitas delas coletivas e próprias daquele contexto. A análise dos contos privilegiou aspectos projetivos grupais, concluindo na direção da necessidade de mais espaços de encontro e troca entre professores e alunos.

PALAVRAS-CHAVE: Educação médica; saúde mental; psicodrama; sociodrama; internato e residência.

1,2,3,4 Professor(a), Departamento de Neurologia e Psiquiatria, Faculdade de Medicina de Botucatu, Universidade Estadual Paulista - Unesp. <ateresa@fmb.unesp.br>; <mclima@fmb.unesp.br>; <torresar@fmb.unesp.br>; <jrtozoni@uol.com.br>.

${ }^{5}$ Psicóloga, Serviço de Apoio Psicológico ao Estudante, Faculdade de Medicina de Botucatu, Universidade Estadual Paulista - Unesp. <nfonseca@fmb.unesp.br>

${ }^{1}$ Departamento de Neurologia e Psiquiatria

Faculdade de Medicina de Botucatu

Distrito de Rubião Júnior, $\mathrm{s} / \mathrm{n}^{\circ}$ 은

Botucatu, SP

$18618-970$ 
É a isto, penso eu, que nos propomos com nossas disciplinas de Psicologia Médica... um trabalho de Sísifo: interminável, inconcluso, sempre reiniciado, cansativo, por vezes tedioso muitas vezes gratificante, mas sempre fascinante e desafiador.

(Eizirik, 1984)

\section{Introdução}

A existência de fontes de estresse durante a formação médica é fato bastante conhecido na literatura. Além do contato com pacientes portadores de doenças graves e muitas vezes potencialmente fatais, outros fatores aumentam os níveis de ansiedade entre os estudantes, tais como: curso longo, ministrado em tempo integral, grande volume de informações, competição entre os colegas, exame de residência e escolha de uma especialidade (Milan et al., 1998).

Alguns autores consideram que existem períodos especialmente estressantes na formação médica (Rocco, 1992; Saadeh, 1995), principalmente no sistema tradicional de ensino que se divide nos ciclos básico, aplicado e internato, cada um deles durando dois anos. Este formato, conhecido como 2-2-2, retarda o contato com o paciente, reforçando a idéia de que o aluno primeiro precisa aprender "tudo" teoricamente, para então estar preparado para o contato com os doentes nos dois últimos anos do curso.

A existência do internato na formação médica foi regulamentada em 1969 pela resolução da Secretaria de Educação Superior (Conselho Federal de Educação, 1969), que estabelecia que as escolas médicas deveriam possuir em seus currículos de graduação um período destinado a treinamento ou aprendizagem em serviço (Marcondes \& Mascaretti, 1998). Recentemente, as novas diretrizes curriculares para os cursos médicos, divulgadas pelo Conselho Nacional de Educação (Conselho Nacional de Educação, 2001), reforçaram o caráter eminentemente prático do internato, e regulamentaram sua duração, que deveria ser de no mínimo dois anos. Inegavelmente a existência do internato foi um avanço, na medida em que determinou um período mínimo de atividade prática intensa e supervisionada. Contudo, essa vivência intensiva acabou por levar o aluno a deparar-se, súbita e cotidianamente, com situações difíceis: o seu próprio limite, os limites de seu paciente e os limites da medicina. Muitas vezes ainda não viveu, de forma gradual, outras situações de encontro com o paciente, com a comunidade e com o sistema de saúde, já entrando em contato com atendimento hospitalar terciário e quaternário.

Há escolas que romperam total ou parcialmente com o formato estanque do ensino médico tradicional, colocando o aluno gradualmente em contato com a prática, com responsabilização crescente e em pequenos grupos (Cyrino, 2002; Lima et al., 2003). No entanto, mesmo nas escolas em que os alunos assumem gradualmente responsabilidade pelos pacientes, é possível que nos últimos anos do curso, quando se sentem próximos de se tornarem médicos, passem a lidar com o luto do papel de aluno, experimentando uma sensação de não haver mais espaço para "o não saber". Segundo Saadeh (1995, p.20): "Em termos profissionais é no 
quinto ano que o amadurecimento pessoal será posto à prova, pois neste momento, define-se uma transformação no ensino, no aprendizado, na postura e nas vivências". Por estas razões, o internato tem sido considerado um dos momentos críticos da formação médica, ao lado da entrada na faculdade e no hospital, no que diz respeito à presença de estresse e ansiedade (Millan et al., 1998; Rocco, 1992; Saadeh, 1995). Soma-se a isto o fato de que no internato os estudantes deverão atuar em pequenos grupos nas diferentes clínicas em que estagiarão, ficando a formação destes grupos a critério da classe, na quase totalidade das escolas. Esta divisão é vivida comumente com intensa angústia (Marcondes, 1993), dada a competitividade e os sentimentos de rejeição que permeiam o processo de escolha, com os quais terão que lidar. Aqueles que não são escolhidos terão que se organizar em grupos com outros colegas igualmente "não escolhidos". Segundo Millan et al. (1998, p.347): "Teme-se ficar no 'lixão', o grupo dos renegados, que é discriminado por alunos e professores".

As experiências desenvolvidas pelas escolas para tentar acolher e diminuir essas angústias descrevem, em geral, trabalhos com pequenos grupos de internos, com foco prioritariamente nas dificuldades profissionais, sobretudo na relação médico-paciente (Saadeh, 1995; De Marco, 1999). Os serviços de atendimento psicológico oferecidos aos alunos, por sua vez, freqüentemente se deparam com estas questões no contexto do atendimento psicoterápico, em geral individual, restringindo uma análise mais coletiva das situações vivenciadas pelo conjunto dos alunos. Em nossa experiência na Faculdade de Medicina de Botucatu (FMB) - UNESP, quer como docentes, quer no atendimento clínico prestado aos alunos, deparamo-nos também com dificuldades vividas pelos alunos na transição para o internato e no término do curso. A constatação destes problemas levou o Conselho de Curso da FMB a solicitar aos professores da área de Saúde Mental (Psiquiatria e Psicologia Médica) e às psicólogas do Serviço de Apoio Psicológico ao Estudante que desenvolvessem estratégias para propiciar o enfrentamento destas dificuldades. O objetivo deste trabalho é descrever uma dessas estratégias, realizada em dois anos consecutivos com os alunos do sexto ano do curso médico, e discutir as possíveis implicações das questões trazidas por eles para o ensino médico como um todo.

Objetivos da atividade

A atividade desenvolvida com os estudantes do $6^{\circ}$ ano teve como objetivos: possibilitar que os alunos identificassem e expressassem aspectos positivos $e$ negativos na sua trajetória acadêmica, assim como sentimentos a ela relacionados; e possibilitar que os alunos resgatassem a identidade da classe como um todo, a partir do compartilhamento dessas vivências e afetos.

\section{Metodologia da atividade}

Participantes: Todos os alunos do $6^{\circ}$ ano da FMB foram convidados a participar da atividade e dispensados de seus estágios no período de realização da mesma (quatro horas de duração, no início do ano letivo).

Instrumento: O Sociodrama, instrumento escolhido para o trabalho 
com os alunos, pertence ao conjunto de estratégias utilizadas no Psicodrama, sendo um recurso técnico a partir do qual é possível trabalhar um tema comum ao grupo, sem que com isto sejam expostos aspectos individuais dos participantes. No método psicodramático os procedimentos terapêuticos podem ser abertos ou fechados. O tratamento aberto, como é o caso do Sociodrama, é realizado no seio da comunidade ("in situ") e a essência é a situação social comum compartilhada por vários sujeitos, para que se avaliem as forças atuantes no grupo (Moreno, 1975). Segundo Menegazzo et al. (1995), este recurso possibilita trabalhar com grupos, visualizando seus conflitos internos e fazendo com que, a partir de sua compreensão, estes conflitos possam ser resolvidos. O Sociodrama nasceu exatamente da necessidade de uma forma especial de Psicodrama, que projetasse seu foco sobre os fatores coletivos. Cada indivíduo vive num mundo que lhe parece inteiramente privado e pessoal, mas os mundos privados se sobrepõem em grande parte, constituindo-se em elementos coletivos ou supra-individuais. Assim, o verdadeiro sujeito do Sociodrama é o grupo, e não cada um dos participantes, não havendo assim espectadores $e$ atores, com todos os sujeitos sendo protagonistas daquela cena - por vasto que seja o grupo, é como um paciente coletivo. O método baseia-se no pressuposto de que o grupo já está organizado pelos papéis sociais $e$ culturais compartilhados. Trata-se de um procedimento particularmente adequado para o estudo das inter-relações culturais de pessoas que estão num processo contínuo de interação e permuta de valores, mas que requer um planejamento cuidadoso (Moreno, 1975).

Procedimentos: O trabalho desenvolveu-se segundo as três fases clássicas do Psicodrama: aquecimento, dramatização e o "sharing" ou compartilhar (quadro1). A coordenação ficou a cargo dos autores deste trabalho, que dirigiram a atividade, propondo técnicas para o aquecimento $e$ favorecimento da produção grupal $e$, ao final, ajudando os alunos na leitura das questões emergentes. Um registro escrito foi elaborado imediatamente após cada vivência por um dos coordenadores e partilhado com os demais, que acrescentaram outras observações consideradas relevantes. A análise da experiência foi discutida e elaborada conjuntamente pelos autores, a partir do delineamento dos temas comuns trazidos pelos alunos.

Análise das cenas: Uma das características do Psicodrama é que não se trabalha com hipóteses pré-concebidas, e o direcionamento é dado pelos conteúdos emergentes, de modo improvisado. Segundo o próprio Moreno, cada sessão é única, original e não se pode repetir. Nem os problemas nem seu percurso são previamente estabelecidos ou "estabelecíveis"(Moreno, 1974). A utilização dos contos de fadas como facilitador da expressão dos sentimentos vivenciados pelos alunos, conduziu à escolha do referencial proposto por Bettelheim na leitura dos contos e seus possíveis significados, contextualizados para o momento do grupo.

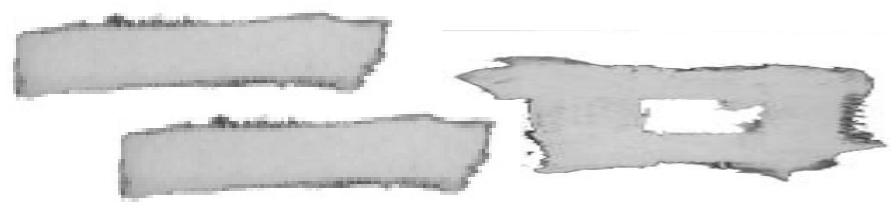


Quadro 1 - Descrição das fases do sociodrama realizado com alunos do $6^{\circ}$. ano do curso médico FMB-UNESP, 2002/2003

\begin{tabular}{|c|l|}
\hline Fase do trabalho & Descrição da orientação dada aos alunos \\
\hline AQUECIMENTO & $\begin{array}{l}\text { Pensar em suas vivências como aluno do curso médico ao longo dos seis anos. } \\
\text { Escolher um conto de fadas, de preferência o primeiro que viesse à mente, que } \\
\text { simbolizasse essa vivência. } \\
\text { Agrupar-se pela similaridade dos contos escolhidos. }\end{array}$ \\
\hline DRAMATIZAÇÃO & Escolher um trecho do conto de fadas e encená-lo para o restante da classe. \\
\hline COMPARTILHAR & $\begin{array}{l}\text { Explicitar os sentimentos evocados com as cenas dramatizadas e, após isto, } \\
\text { cada pequeno grupo formado a partir das escolhas dos contos de fada } \\
\text { elaboraria um trecho que deveria compor o discurso de formatura, que seria lido } \\
\text { para todos. }\end{array}$ \\
\hline
\end{tabular}

Resultados

A participação dos alunos variou de $90 \%$ (grupo de 2002) a 40\% (grupo de 2003) nos dois anos em que a atividade foi desenvolvida. Os contos de Fada dramatizados foram: Branca de Neve e os sete anões, Os três porquinhos, João e o Pé de Feijão, Pinóquio, Cinderela, O patinho feio, "Shrek", A Cigarra e a Formiga, Chapeuzinho Vermelho, A Tartaruga e a Lebre, $A$ galinha ruiva, $A$ bela adormecida e $A$ galinha e a águia. Outros contos que não foram dramatizados em função de terem sido escolhidos por apenas uma pessoa foram: Os doze trabalhos de Hércules, Dumbo, O mágico de $\mathrm{Oz}$, A galinha dos ovos de ouro, João e Maria e A raposa e as uvas.

De modo geral, observou-se que as dramatizações expressavam a expectativa com os exames finais (residência médica $e$ "provão-MEC6") $e$ uma espécie de balanço da relação com a instituição. Surgiram também

${ }^{6}$ Referência ao Exame Nacional de Cursos, do Ministério da Educação. manifestações que podem ser interpretadas como fantasias paranóides e depressivas (estar na Faculdade há tanto tempo e "não saber nada", inseguranças, medo do desempenho, medo de não passar no exame de residência, de ser preterido pelos professores, medo de ir mal no "provão" etc). Resistências ao trabalho psicodramático puderam ser observadas na fase de aquecimento $e$ escolha das cenas, quando alguns alunos referiam, por exemplo, não conseguir escolher entre os diversos contos que lhe vinham à mente e mesmo na dificuldade de alguns no aquecimento. Em todo o processo de trabalho foram observados movimentos de solidariedade $e$ identificação intra-grupo. Os "discursos finais de formatura" explicitaram essa identificação, na medida em que formaram conjuntos homogêneos de conteúdo, pela soma das produções de cada subgrupo.

\section{Discussão}

Historicamente o Psicodrama se origina dos princípios do jogo e é reconhecido o valor educacional da brincadeira, tão antiga quanto a humanidade. A utilização dos contos de fadas (que poderiam ter sido substituídos por outros recursos culturais comuns como provérbios, filmes, letras de músicas etc) funcionou de certa forma apenas como um veículo entre a fantasia e a experiência de realidade, permitindo de forma indireta, espontânea, criativa e lúdica a emergência de temas e afetos individuais, que foram então analisados em seus aspectos comuns, propiciando a identidade 
e a coesão grupal. Portanto, a técnica apenas estimulou a expressão verdadeira das situações e conflitos reais, por meio da dramatização. Espontaneidade e criatividade são pilares conceituais do psicodrama moreniano, condições indispensáveis para o bom desenvolvimento dos diferentes papéis sociais, pelos quais se dão todas as relações humanas, tanto mais saudáveis quanto mais flexíveis, espontâneas e criativas (Moreno, 1974).

Sobre a aplicação dos contos no Psicodrama, Zamboni afirma que:

Os contos de fadas são dirigidos às crianças; mas pelo valor simbólico, se dirigem a todas as idades, falando com seriedade, de forma breve e categórica, dos dilemas e ansiedades existenciais como o medo da morte, de não ser amado, de não ter valor etc... (Zamboni, 1984, p.162)

Bettelheim é, entre outros, o responsável por difundir uma leitura dos contos de fadas a partir dos pressupostos da Psicanálise (Bettelheim, 1992). Em "A Psicanálise dos contos de fadas", o autor busca apreender os significados que estariam implícitos nos contos, para tentar compreender como eles sobreviveram por centenas de anos. Utilizando as propostas de análises de Bettelheim ${ }^{7}$ para os contos apresentados pelos alunos, observouse uma série de dificuldades e conflitos que poderiam estar subjacentes às escolhas dos contos. O conflito entre o princípio do prazer e o princípio da realidade que, segundo Bettelheim, é o eixo de contos como "Os três porquinhos" e "A cigarra e a formiga", parece refletir as escolhas que estes alunos tiveram que fazer ao longo do curso: não ir às festas por estar de plantão ou não visitar os pais por terem que estudar para provas, entre tantas outras renúncias. Após seis anos de muitas renúncias - para não mencionar as dos anos de cursinho descritos pelos alunos como de intensos estudos e sacrifícios - é esperado que haja uma recompensa. É o que se vê em "Cinderela" e "João e o Pé de Feijão". Neste último conto, Bettelheim chama a atenção para o significado simbólico da escalada que João faz no pé de feijão: ele se torna mais adulto, amadurece e só assim é capaz de enfrentar o gigante (ter sucesso nas provas de residência, boa classificação em concursos, ser valorizado pela instituição).

Em praticamente todos os contos os heróis recebem sua recompensa e os inimigos são castigados, como o lobo de "Chapeuzinho Vermelho" e "Os três porquinhos". Porém, depois do percurso na Faculdade de Medicina, o futuro lhes parece ainda incerto: sentem-se inseguros, não sabendo se a recompensa virá para eles. Em breve não estarão mais sob a tutela da Escola/ Mãe, experimentando neste momento de passagem uma crise de identidade semelhante àquela observada na adolescência (Aberastury, 1988). Pode-se supor que contos como "Pinóquio", "O Patinho Feio" e "A Galinha e a Águia”, reflitam estas inseguranças. Não saber se é pato ou cisne, se é (será) bom ou mau médico, são dúvidas prevalentes neste momento de final de curso.

Sabe-se que há poucas oportunidades de troca entre os alunos no que diz respeito aos problemas, medos, culpas, angústias e outros sentimentos que

\author{
${ }^{7}$ As análises que \\ Bettelheim faz para os \\ contos de fada dizem \\ respeito a aspectos \\ importantes do \\ desenvolvimento \\ emocional das pessoas. \\ A intenção nesta \\ discussão é adaptá-las a \\ um outro objeto: ao \\ universo emocional de \\ estudantes de medicina \\ em final de curso. \\ Ainda que a \\ transposição seja difícil, \\ acreditamos que \\ contribua para a \\ reflexão das \\ experiências emocionais \\ desses alunos.
}

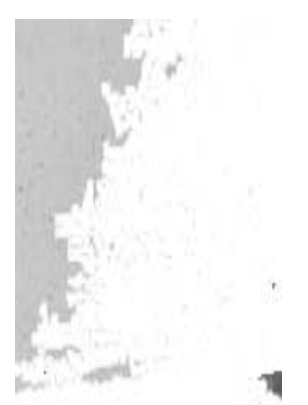


surgem no cotidiano da relação médico/aluno/paciente. A respeito disto, Millan et al. (1998, p.141) afirmam que:

A falta de um espaço para a troca de idéias a respeito dessas experiências contribui para acentuar o isolamento, trazendo a crença de que se trata de um problema único que não pode ser compartilhado, pois ninguém mais estaria passando por isso $e$ não o compreenderia.

No presente trabalho, os autores tinham como pressuposto que a verbalização de angústias, ansiedades e medos, assim como a expressão cênica dos mesmos, possibilitariam uma melhor elaboração destes sentimentos e melhorariam a organização grupal. Trabalhar com a classe toda possibilitou que os alunos reencontrassem os colegas de turma, agora em outros subgrupos, e restabelecessem a identidade junto aos pares, na medida em que puderam expressar coletivamente as dificuldades pertinentes a este momento da formação.

A utilização de jogos e dramatizações também pareceu auxiliar a expressão dos afetos experimentados pelos alunos. Freqüentemente, durante a formação médica há momentos de extremo desencantamento com relação à prática profissional quando confrontada com a visão idealizada com a qual o aluno chega à escola. Este desencantamento leva muitas vezes ao desenvolvimento de mecanismos de defesa perante o sofrimento dos pacientes e um distanciamento, não apenas destes doentes, mas também de sua própria experiência emocional (Martins, 1994). Para Cassorla (1994, p.23)

existe uma dificuldade imensa dos médicos em lidar com os aspectos emocionais de seus pacientes (e, evidentemente, também dos próprios médicos). Muitos procuram fugir destes aspectos, reduzindo sua atividade à abordagem do biológico.

"Brincar" com os contos de fadas, "inocentes" lembranças de suas infâncias, auxiliou na diminuição das resistências e catalisação dos afetos e angústias. No caso, pode-se supor que o procedimento sociodramático utilizado não teve apenas valor exploratório de atitudes e sentimentos, mas pode também ter propiciado modificações nos grupos envolvidos, não apenas por seu efeito catártico, como também "iluminador".

Cabe uma reflexão sobre a diferença de participação nos dois anos em que a atividade foi conduzida. Embora os dois grupos de alunos soubessem que seria conduzida uma atividade com técnicas psicodramáticas, havia algumas diferenças entre eles: o primeiro havia passado por uma série de inovações curriculares ao longo do seu curso, tendo vivenciado inclusive um sociodrama em seu primeiro ano de curso. O segundo grupo possuía um número maior de alunos ( $25 \%$ a mais) e provavelmente já estavam de posse de maiores detalhes sobre a atividade, sendo possível que parte dos alunos tenha se ausentado em função das resistências a trabalhar com suas dificuldades. A direção da escola $e$ as instâncias que tratam de problemas dos 
alunos forneceram todo o apoio necessário, não interferindo no trabalho desenvolvido e possibilitando a livre expressão dos alunos.

\section{Considerações finais}

O internato, assim como outros momentos da formação médica, é fonte potencial de sofrimento psíquico, havendo a necessidade de colocar o tema em pauta e desenvolver estratégias de manejo destas dificuldades. O Sociodrama é uma das estratégias possíveis, na medida em que possibilita a expressão de afetos comuns ao conjunto dos alunos, sem expor a fragilidade de cada um dos indivíduos. Para que o trabalho se desenvolva, é fundamental que o papel da Instituição não seja de fiscalização, mas sim o de fornecer espaço de acolhimento para coordenadores e alunos. Apesar das dificuldades apontadas, houve predomínio, no final, de uma postura otimista por parte dos alunos $e$ um sentido de fortalecimento pela coesão/identidade grupal.

As novas diretrizes curriculares para o ensino médico no país têm estimulado a existência de atividades práticas desde os primeiros anos do curso, em especial atividades junto às comunidades locais e em programas que estimulem um olhar mais humanizado e mais próximo das necessidades das populações. É possível que as mudanças curriculares propiciem também mudanças em relação aos níveis de ansiedade e estresse vivenciados pelos alunos. Avaliações deverão ser conduzidas com a finalidade de mensurar o impacto que as mudanças terão tanto sobre a qualidade do profissional como também sobre o grau de estresse presente no processo formativo.

Obviamente, uma única atividade ilhada no meio de seis anos de percurso não tem por si só a força transformadora necessária para aliviar de modo significativo o estresse e humanizar o ensino médico. Na verdade, estudantes $e$ professores das escolas médicas necessitam de muitos e de amplos espaços para reflexão e catarse. Na cena de Pinóquio, trazida pelos alunos, a fada o toca com a varinha de condão e diz: "Antes você era um médico de pau e agora você é um médico de verdade". Esta cena protagoniza a necessidade de ampliarmos os espaços de humanização nas escolas médicas - para alunos e professores - $e$ talvez este seja o toque "mágico" para que formemos menos "médicos de pau" e mais médicos "de verdade".

\section{Referências}

ABERASTURY, A; KNOBEL, M. Adolescência normal. 6.ed. Porto Alegre: Artes Médicas, 1988.

BETTELHEIM, B. Psicanálise dos contos de fada. 9.ed. Rio de Janeiro: Paz e Terra, 1992.

CASSORLA, R. M. S. Dificuldades no lidar com aspectos emocionais na prática médica: estudo com médicos no início de grupos Balint. Rev. ABP-APAL, v.16, n.1 p.18-24, 1994.

CONSELHO FEDERAL DE EDUCAÇÃO. Resolução n.8, outubro de 1969. Dispõe sobre a criação de internato nos cursos médicos. Brasília, 1969.

CONSELHO NACIONAL DE EDUCAÇÃO. Diretrizes curriculares nacionais do curso de graduação em medicina. Câmara de educação Superior, Resolução n.4, 7 de novembro de 2001. Brasília, 2001.

CYRINO, E. G. Desafios à reforma curricular da Faculdade de Medicina de Botucatu: as iniciativas de mudanças e a avaliação dos cursos de Pediatria e Saúde Coletiva do $3^{\circ}$. ano médico. 2002. Tese (Doutorado) - Faculdade de Medicina de Botucatu, Botucatu. 
DE MARCO, O. L. N. Grupos de reflexão com quintanistas de Medicina. In: MILLAN, L. R.; DE MARCO, O. L. N.; ROSSI, E.; ARRUDA, P. C. V. (Orgs.) Universo psicológico do futuro médico. São Paulo: Casa do Psicólogo, 1999. p.129-48.

EIZIRIK, C. L. Ensinando uma profissão impossível. Rev. ABP-APAL, v.16, n.1 p.133-5, 1984.

LIMA, G. Z.; ALMEIDA, H. G. G.; FERREIRA FILHO, O. F.; LINHARES, R. E. C.; OBERDIEK, H. I.; COLUS, I. M. S. Aprendizagem baseada em problemas (ABP): construindo a capacitação em Londrina, Brasil. Rev. Bras. Educ. Méd, v.27, n.1 p.5-11, 2003.

MARCONDES, E. Distribuição dos alunos pelos grupos de internato: uma questão importante. Bol. Ponto e Vírgula, v.23, n.4, s/p.,1993.

MARCONDES, E.; MASCARETTI, L. A. S. O internato na graduação médica. In: MARCONDES, E.; GONÇALVES, E. L. (Orgs.) Educação médica. São Paulo: Savier, 1998. p.149-66.

MARTINS, L. A. N. Residência médica: um estudo prospectivo sobre dificuldades na tarefa assistencial e fontes de estresse. 1994. Tese (Doutorado) - Escola Paulista de Medicina, São Paulo.

MENEGAZZO, C. M.; TOMAZINI, M. A.; ZURETTI, M. M. Dicionário de psicodrama e sociodrama. São Paulo: Agora, 1995.

MILLAN, L. R.; SOUZA, E. N.; DE MARCO, O. L. N.; ROSSI, E. Assistência psicológica ao estudante de medicina. In: MARCONDES, E.; GONÇALVES, E. L. (Orgs.) Educação médica. São Paulo: Savier, 1998. p.340-54.

MORENO, J. L. Psicoterapia de grupo e psicodrama: introdução à teoria e à praxis. São Paulo: Mestre Jou, 1974.

MORENO, J. L. Psicodrama. São Paulo: Cultrix, 1975.

ROCCO, R. P. Relação estudante de medicina-paciente. In: MELLO FILHO, J. (Org.) Psicossomática hoje. Porto Alegre: Artes Médicas, 1992. p.45-56.

SAADEH, A. Internato em medicina: estudo da interação estudante-paciente. 1995. Dissertação (Mestrado). Faculdade de Medicina, Universidade de São Paulo, São Paulo.

ZAMBONI, N.G. Os contos de fada no psicodrama. Rev. FEBRAP, v.7, p.161-7, 1984.

RAMOS-CERQUEIRA, A. T. A. et al. Había una vez ... los cuentos de hadas y el psicodrama ayudando alumnos que están concluyendo el curso medico, Interface - Comunic., Saúde, Educ., v.9, n.16, p.81-9, set.2004/fev.2005.

El término del curso representa un período especialmente estresante para los estudiantes de medicina, en el que se deparan con diversas angustias: abandonar el papel de alumno, asumir nuevas responsabilidades y enfrentar el examen de residencia. Con la intención de ayudarlos en esta fase, la Facultad de Medicina de Botucatu (FMB) creó una serie de estrategias de acogimiento para los estudiantes. En este estudio se describe una actividad en la cual se utilizó el Psicodrama como facilitador de la expresión de sentimientos y emociones vivenciadas al final del curso. Por dos años consecutivos fueron realizados Sociodramas con los alumnos del ultimo año del curso de medicina. Se utilizaron los cuentos de hadas como recurso para que los estudiantes identificasen su trayectoria dentro de la institución y el momento que estaban viviendo. La dramatización de los cuentos posibilitó el intercambio de experiencias entre los alumnos y el acogimiento de sus angustias, que en su mayoría eran colectivas y propias de aquel contexto. El análisis de los cuentos privilegió aspectos proyectivos grupales llevando a la conclusión de que son necesarios más espacios de encuentro e intercambio entre profesores y alumnos.

PALABRAS CLAVE: Educación Médica; salud mental; internato; psicodrama; sociodrama. 

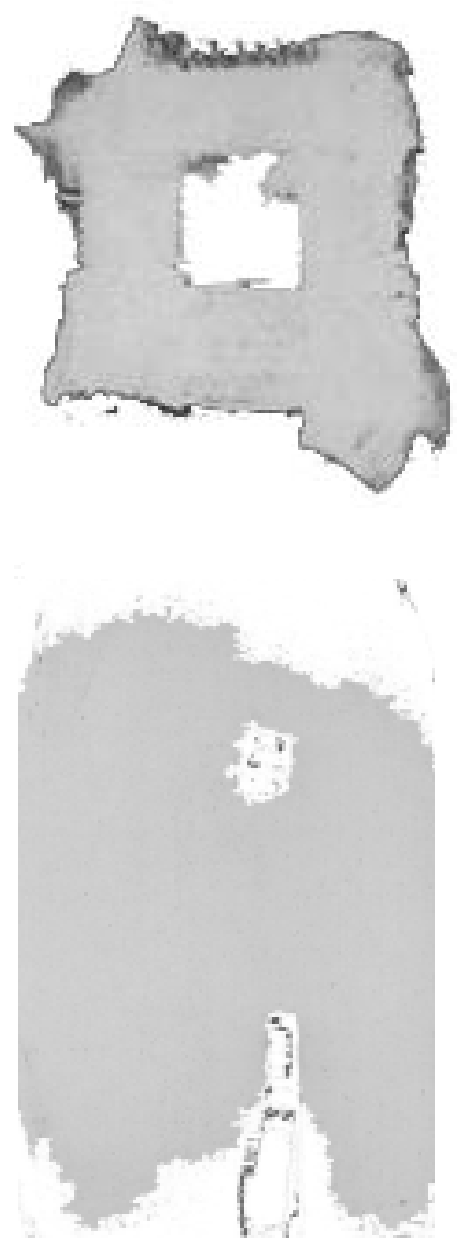

90 Interface - Comunic, Saúde, Educ, v.9, n.16, p.90, set.2004/fev.2005 